\title{
Abdelkader Djemaï, Il naso contro il vetro (Le nez sur la vitre)
}

\section{Ilaria Vitali}

\section{(e) OpenEdition}

1 Journals

\section{Edizione digitale}

URL: http://journals.openedition.org/studifrancesi/7740

DOI: 10.4000/studifrancesi.7740

ISSN: 2421-5856

\section{Editore}

Rosenberg \& Sellier

\section{Edizione cartacea}

Data di pubblicazione: 1 décembre 2009

Paginazione: 676-677

ISSN: 0039-2944

\section{Notizia bibliografica digitale}

Ilaria Vitali, «Abdelkader Djemaï, II naso contro il vetro (Le nez sur la vitre)», Studi Francesi [Online], 159 (LIII | III) | 2009, online dal 30 novembre 2015, consultato il 09 janvier 2021. URL: http:// journals.openedition.org/studifrancesi/7740 ; DOI: https://doi.org/10.4000/studifrancesi.7740

Questo documento è stato generato automaticamente il 9 janvier 2021.

\section{(c) (i) $\odot$}

Studi Francesi è distribuita con Licenza Creative Commons Attribuzione - Non commerciale - Non opere derivate 4.0 Internazionale. 


\title{
Abdelkader Djemaï, Il naso contro il vetro (Le nez sur la vitre)
}

\author{
Ilaria Vitali
}

\section{NOTIZIA}

ABDELKADER DJEMAï, Il naso contro il vetro (Le nez sur la vitre), trad. di Enrica RIZZINI, Brescia, Bibliofabbrica, 2008, pp. 69.

1 Chi ha letto Abdelkader Djemaï conosce l'immediatezza della sua prosa, la sua abilità nel trascinare il lettore nell'universo finzionale e la bellezza struggente della sua scrittura, limpida e intensa, che costituiscono la cifra stilistica della sua narrativa. Tutti elementi che si ritrovano anche nel romanzo breve Il naso contro il vetro (Le nez sur la vitre), edito in Italia da Bibliofabbrica, nella bella traduzione di Elena RIzziNI. Raggiunge così il pubblico italiano un piccolo gioiello della letteratura maghrebina di lingua francese. Il naso contro il vetro mette al centro un uomo alla ricerca del figlio che non risponde più alle sue lettere. In un giorno d'estate, «nella luce cretacea del primo mattino» (p. 12), l'uomo lascia la famiglia e sale su un autobus, "caraffa di cristallo inondata di sole» (p. 14), sulle tracce del ragazzo. Come è facile immaginare, il viaggio fisico, esterno, del protagonista diviene presto viaggio interiore. In un intreccio di passi a ritroso verso ricordi passati (un altro autobus, un altro paese, la guerra, la miseria) e slanci verso aspirazioni future (superare il «vetro» dell'incomprensione e ritrovare il figlio), tempi e spazi diversi si sovrappongono fino a fondersi. Torna alla mente la definizione bachtiniana di cronotopo, fusione dei connotati spaziali e temporali in un tutto dotato di senso e concretezza, che assume un valore particolare se applicata alla letteratura maghrebina. Dietro il vetro dell'autobus, riaffiora così l'immagine dolorosa dell'Algeria, paese d'origine dell'uomo, emigrato in Europa per offrire un futuro migliore ai suoi figli. «Era stato guardando le navi allontanarsi che il desiderio di lasciare il paese si era un giorno insinuato in lui» (p. 51). Tuttavia, la vita in Francia ha un amaro contraltare: l'uomo si accorge presto che il figlio, «secco e nodoso», non sa nulla della sua famiglia d'origine. «Ben presto, per forza di cose e del tempo, era 
divenuto orfano di una storia famigliare con i suoi drammi e le sue gioie, la sua forza e le sue difficoltà, i suoi elementi di unione e le sue divisioni. [...] era irrimediabilmente, definitivamente di qui» (p.59). Nell'andirivieni della memoria da una sponda all'altra del Mediterraneo, la realtà urbana (gli edifici popolari, il reticolo di strade e autostrade, il tragitto in comune di persone sconosciute, l'intreccio di destini di un'umanità meticcia) rimane sempre presente sullo sfondo, senza tuttavia opporsi all'universo rurale, ma anzi segnandone il prosieguo senza soluzione di continuità (l'autore stesso è fiero di definirsi un «rurbain»).

2 Lo stile di Djemaï è semplice, senza orpelli, la lingua classica, ben resa dall'elegante traduzione di Elena Rizzini. Vi si scorge l'esperienza di giornalista dell'autore, che ha più volte dichiarato di non amare le contorsioni linguistiche, sorta di «patinage artistique» che distoglie dall'essenziale. Colpisce l'assenza di dialoghi, che sembra sottolineare in modo ancora più forte i silenzi carichi d'emozione del protagonista, analfabeta. Scegliendo la semplicità e l'immediatezza dello stile, Djemaï afferma ancora una volta la sua volontà di far entrare dentro la storia il lettore, che diviene presto il compagno di viaggio del silente protagonista dal «naso contro il vetro». Insieme a lui, osserva il paesaggio giallo e piatto, sfilare fuori dal finestrino del Setra Kässbohrer a sospensione pneumatica, fino al capolinea. Un romanzo toccante, dal finale sorprendente e amaro, che non lascerà indifferente chi legge. 